\title{
LGR5 and LGR6 in stem cell biology and ovarian cancer
}

Review

\author{
Adam J. Schindler ${ }^{1}$, Arisa Watanabe ${ }^{1}$ and Stephen B. Howell ${ }^{1}$ \\ ${ }^{1}$ Moores Cancer Center, University of California, San Diego, CA, USA \\ Correspondence to: Stephen B. Howell, email: showell@ucsd.edu \\ Keywords: ovarian cancer, Wnt, LGR6, LGR5, RSPO
}

Received: June 14, 2017 Accepted: July 31, $2017 \quad$ Published: August 11, 2017

Copyright: Schindler et al. This is an open-access article distributed under the terms of the Creative Commons Attribution License 3.0 (CC BY 3.0), which permits unrestricted use, distribution, and reproduction in any medium, provided the original author and source are credited.

\section{ABSTRACT}

Wnt signaling plays a fundamental role in patterning of the embryo and maintenance of stem cells in numerous epithelia. Epithelial stem cells are closeted in niches created by surrounding differentiated cells that express secreted Wnt and $\mathbf{R}$-spondin proteins that influence proliferation rate and fate determination of stem cell daughters. R-spondins act through the LGR receptors to enhance Wnt signaling. This close association of stem cells with more differentiated regulatory cells expressing Wnt-pathway ligands is a feature replicated in all of the epithelial stem cell systems thus far examined. How the stem cell niche operates through these short-range interactions is best understood for the crypts of the gastrointestinal epithelium and skin. Less well understood are the stem cells that function in the ovarian surface epithelium (OSE) and fallopian tube epithelium (FTE). While the cuboidal OSE appears to be made up of a single cell type, the cells of the FTE progress through a life cycle that involves differentiation into ciliated and secretory subtypes that are eventually shed into the lumen in a manner similar to the gastrointestinal epithelium. Available evidence suggests that high grade serous ovarian carcinoma (HGSOC) originates most often from stem cells in the FTE and that Wnt signaling augmented by LGR6 supports tumor development and progression. This review summarizes current information on LGR5 and LGR6 in the OSE and FTE and how their niches are organized relative to that of the gastrointestinal epithelium and skin.

\section{INTRODUCTION}

Wnt proteins activate at least two major intracellular pathways, the canonical and non-canonical Wnt signaling pathways. In the canonical pathway, the binding of Wnt ligands to the cell-surface receptors Frizzled (FZD) and LDL-receptor related protein 5/6 (LRP5/6) leads to the phosphorylation of the LRP receptor and degradation of intracellular GSK $3 \beta$. This frees $\beta$-catenin to migrate to the nucleus and form a complex with TCF/LEF, driving transcription of a large number of genes involved in cell proliferation and stem cell self-renewal [1].

In addition to Wnts, a second type of ligand secreted from the niche, the R-spondin (RSPO), also regulates Wnt signaling in stem cells. The four isoforms of RSPO (RSPO1-4) are ligands for three transmembrane receptors, leucine-rich repeat-containing G-protein coupled receptors 4-6 (LGR4-6) [2, 3]. As shown schematically in Figure 1, RSPO binding to LGR4-6 enhances Wnt signaling by inhibiting negative regulators of the Wnt pathway. Among the genes upregulated by $\beta$-catenin are ZNRF3 and RNF43, functionally homologous cell-surface transmembrane proteins that ubiquitinate FZD and LRP5/6 receptors, leading to their endocytosis and degradation by the lysosome. This has the effect of dampening Wnt signaling as part of a negative feedback loop [4, 5]. RSPOs bind simultaneously to the extracellular domains of LGR4-6 and ZNRF3/RNF43, forming a ternary complex that is cleared from the membrane. This results in prolonged cell-surface residence time of FZD and LRP5/6 and enhancement of Wnt signaling [6, 7]. Hao et al. elegantly demonstrated that the proximity of ZNRF3/RNF43 to LGR4-6 is crucial for membrane clearance by engineering a dimerization interface between ZNRF3 and LGR4, which resulted in loss of ZNRF3 from the membrane upon treatment with the dimerizer [8]. RSPO proteins therefore serve as matchmakers to join LGR4-6 with ZNRF3/ RNF43. The exact mechanism of membrane clearance 
is yet to be determined but depends on the intracellular RING domain of ZNRF3/RNF43 [8].

LGR5 and LGR6 have gained prominence because they are among the few known stem cell-specific receptors. Studies in mice have shown that LGR5 marks epithelial stem cells in the intestine, hair follicle, kidney, mammary gland, colon, and ovary [9-13]; LGR6 marks stem cells in the epidermis, mammary gland, nail, and fallopian tube [14-17]. The presence of LGR5 and LGR6 on stem cells is consistent with the elevated Wnt signaling in these cells. Importantly, LGR5 and LGR6, and their ligands RSPO1-4, are upregulated in several cancers, lending support to the idea that elevated Wnt signaling may be a driver of tumor formation [18-21]. The third RSPO receptor, LGR4, is expressed more broadly and is not a marker of stem cells per se [22, 23], although it has important roles in intestinal morphogenesis [24], hair, prostate, and mammary gland development [25-27], and tumor formation and metastasis [28-31]. This review will focus on the regulation of epithelial stem cells by LGR5 and LGR6 and the contribution of this signaling pathway to tumor formation and chemoresistance. Particular emphasis will be given to stem cells of the ovary and fallopian tube epithelia, two tissues that are implicated in ovarian cancer formation.

\section{Organization of the intestinal stem cell niche}

In the mouse intestinal epithelium, stem cells are located at the base of the crypts and are intercalated with differentiated Paneth cells. The stem cells are marked by their expression of FZD and LGR5 receptors, while Paneth cells express CD24 and secrete EGF, TGF $\alpha$, Wnt3 and the Notch ligand Dll4 [32]. Paneth cells are an important source of ligands for the receptors that support stem cell function. As the stem cells divide, they give rise to daughters that either remain as stem cells in the

\section{Basal WNT signaling}

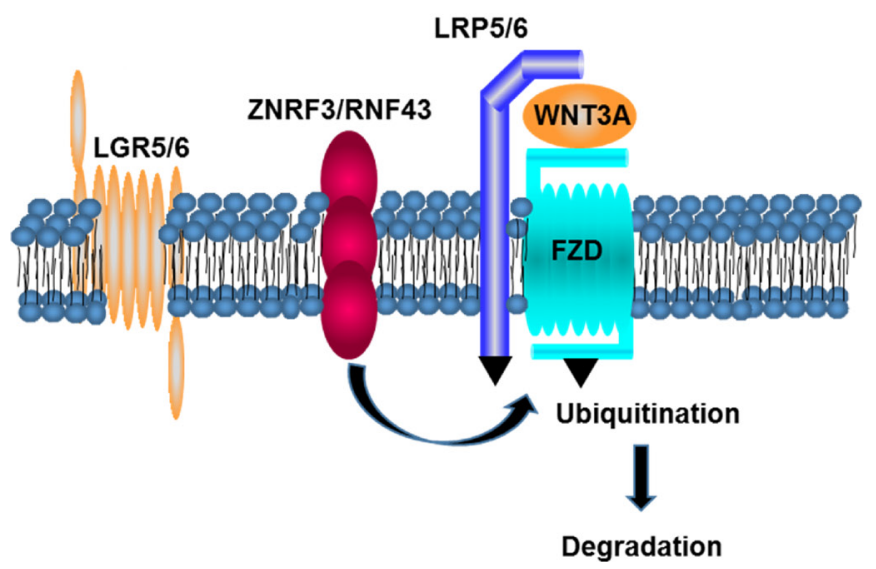

niche or become transit-amplifying cells that differentiate along several lines. Some transit-amplifying cells become Paneth cells and remain at the base of the crypt, while others proliferate and migrate up the side wall of the crypts in a conveyor belt-like fashion as they become absorptive epithelium cells, goblet cells, and enteroendocrine cells. After service on the gut surface for several days, they undergo apoptosis and are lost into the lumen [33, 34].

There are 19 human Wnt ligands and 10 FZD receptors, making it a considerable challenge to identify the combinations that are important in stem cell function. In contrast, the lower number of RSPOs and LGRs has allowed characterization of their expression and roles in stem cells. In the mouse intestinal crypt, LGR5 marks a cell at the crypt base that can generate all of the cell types found on the villus [35]. The expression level of the RSPOs is crucial for maintaining the proper number of stem cells and limiting tissue growth [36-38]. Overexpression of $\mathrm{RSPO1}$ or $\mathrm{RSPO} 2$ in mice resulted in crypt hyperplasia and increased expression of Wnt target genes [36, 38]. Similarly, RSPO3 overexpression caused intestinal hyperplasia and the formation of adenomas that sometimes progressed to adenocarcinomas [37]. These studies show that limiting the amount of RSPO1-3 is important in preventing aberrant cell growth, but do not allow a clear determination of the native RSPOs that regulate stem cell function in the crypt. RSPOs can substitute for each other in tissue culture experiments [7], and it is plausible that high-level expression of any isoform, results in increased Wnt activity and hyperplasia.

Surprisingly, neither RSPO1 nor LGR5 are necessary for the wellbeing of the murine gut epithelium under steady-state conditions, although both appear to play a role in recovery from injury. Knockout of RSPO1 in mice caused aberrant ovarian masculinization, but

\section{RSPO1/2 augmentation of WNT signaling}

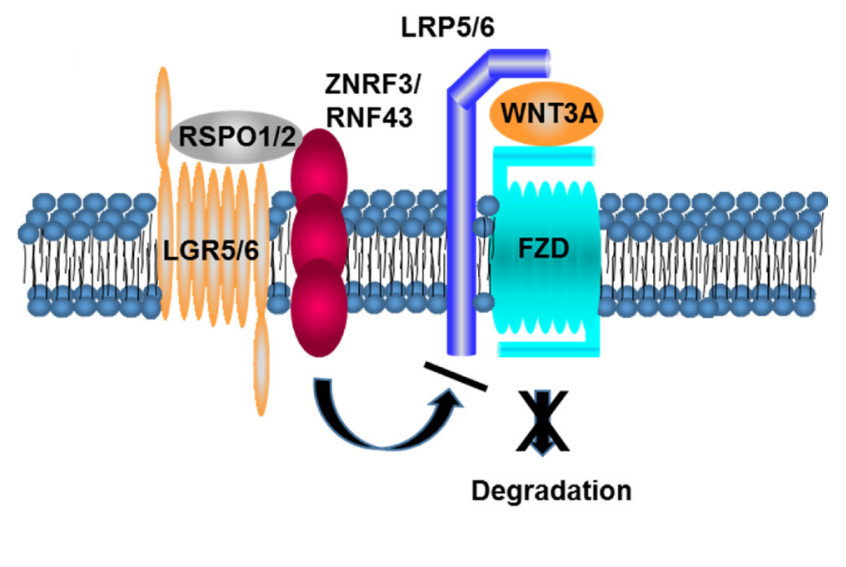

Figure 1: RSPO augmentation of Wnt signaling. Left panel: In the absence of RSPO1/2, ubiquitin ligases ZNRF3 and RNF43 ubiquitinate LRP5/6 and FZD receptors, which marks them for lysosomal degradation and limits their residence time on the cell surface. Right panel: Binding of RSPO1 or RSPO2 to LGR5 or LGR6 causes the receptor to clear ZNRF3/RNF43 from the membrane, which prolongs the plasma membrane residence time of LRP5/6 and FZD and augments Wnt signaling. 
no reported defects in intestinal development [39-41]. Humans with hereditary loss of RSPO1 have the skinthickening condition palmoplantar hyperkeratosis, increased susceptibility to squamous cell carcinoma, and $\mathrm{XX}$ sex reversal, but no reported intestinal abnormalities [42, 43]. Conditional knockout of LGR5 in adult mice similarly caused no apparent defects in intestinal structure, possibly due to the presence of LGR4 in the stem cell population [3]. This lack of intestinal defects in RSPO1and $L G R 5$-null mice likely reflects the fact that Wnt signaling still occurs in the absence of these genes, and this is apparently sufficient for normal tissue development and maintenance. Following injury, however, Wnt signaling increases [44], and RSPO1 and LGR5 become important in recovery of the epithelium. When intestinal cells were killed by the chemotherapeutic agent 5-fluorouracil, overexpression of recombinant $R S P O 1$ ameliorated cell loss [36]. Mice overexpressing RSPO1 also had improved structural and functional regeneration of the intestine, including recovery of stem cell populations, following abdominal irradiation [45]. When LGR5-expressing cells were depleted in the crypt prior to radiation treatment, the crypt failed to regenerate [46]. These results demonstrate that the increase in Wnt activity that facilitates recovery from injury occurs at least in part through RSPO signaling to LGR receptors.

A central question in Wnt stem cell biology is how RSPO and Wnt ligands cooperatively control stem cell self-renewal and differentiation. An important recent paper from Yan et al. helped define the roles of each ligand in mouse intestinal crypt stem cells [38]. RSPOs regulate the size of the stem cell pool, as overexpression of $R S P O 1$ or $R S P O 2$ resulted in the expansion of $\mathrm{LGR}^{+}$ stem cells. Reduction in RSPO signaling through the expression of the ectodomains of RSPO-binding proteins caused a marked loss of stem cells and an increase in differentiated progeny. In contrast, expression of a Wnt ligand analogue did not regulate stem cell number, but was required for stem cell expansion in response to RSPO. Inhibition of Wnt ligands resulted in lower expression of $L G R 5, Z N R F 3$, and $R N F 43$, demonstrating that Wnt ligands prime stem cells for RSPO signaling through the expression of its receptors [38]. These results are consistent with the finding that RSPO1 and LGR5 are expendable for normal function of the intestine when stem cell populations are static, but are important for stem cell expansion following injury. In regard to cancer, stem cells are relatively resistant to chemotherapeutic agents $[47,48]$, and increased levels of LGR5 correlate with chemoresistance [49-51], suggesting that LGR signaling may promote the recovery of a cancer stem cell population following chemotherapy.

\section{LGRs and Wnt signaling in skin stem cells}

The stem cell niches of other epithelia differ in their morphology but appear to have a similar structural organization to the intestine, in which stem cells are supported by factors released from cells in their immediate environment [52]. In the adult mouse skin, stem cell populations that regulate the interfollicular epidermis (IFE) and hair follicle (HF) have been identified in the basal layer of the IFE, the bulge and hair germ regions of the HF, and the sebaceous gland [53]. The individual populations of stem cells are multipotent and capable of regenerating different structures in the skin following injury [54]. Among the LGR proteins, the mostly likely contributors to Wnt signaling in the HF are LGR4 and LGR5, the latter of which was found in an actively cycling population in the hair germ that was capable of reconstituting hair follicles when grafted onto nude mice [11].

While the population of $\mathrm{LGR}^{+}$cells were found to control HF growth, they did not contribute to the growth or self-renewal of the sebaceous gland or IFE [11]. Instead, these tissues express LGR6, demonstrating heterogeneity in the type of LGR receptor on stem cells within an organ [14]. Although initially thought to function independently of Wnt [14], mouse IFE stem cells in the basal epidermis were shown to express the canonical Wnt marker Axin2, and inhibition of $\beta$-catenin reduced proliferation [55]. Thus, LGR6 in IFE cells is likely functioning in a canonical manner to regulate Wnt activity in the stem cell population. Interestingly, the IFE stem cells function as their own niche by expressing Wnt ligands, an example of autocrine signaling within the stem cell environment [55].

The expression of LGR5 and LGR6 in skin stem cells and the role of Wnt signaling suggests the presence of RSPOs as ligands, although few studies have examined this. The first evidence for RSPO function in skin was through mapping of a familial propensity to palmoplantar hyperkeratosis and squamous cell carcinoma to loss-of-function mutations in RSPO1 [42]. Later molecular characterization in mice showed that all four isoforms of RSPO were expressed in the skin, and that overexpression of RSPO1 activated the Wnt pathway, including increased expression of $L G R 5$, and resulted in defects in HF growth [56]. RSPO2 also is linked to skin and hair development. Keloids, raised scars caused by overgrowth of granulation tissue, contain keratinocytes that express elevated levels of RSPO2 [57]. Studies on the genetic basis of coat variation in domestic dogs have found linkage between alleles of RSPO2 and fur type $[58,59]$. These findings indicate a role for RSPO/LGR activity in skin and skin appendage development, and further demonstrate that tight regulation of Wnt signaling is important for maintaining the normal function of stem cells.

\section{Wnt signaling in ovarian and fallopian tube stem cells and ovarian cancer}

Ovarian cancer is the fifth-leading cause of cancer deaths among women in the United States. The most 
common and malignant type of ovarian cancer is high grade serous ovarian carcinoma (HGSOC). The tissue origins of HGSOC are controversial, and have been attributed to two juxtaposed epithelia: the ovarian surface epithelium (OSE) that encapsulates the ovary, and the fallopian tube epithelium (FTE) at the distal end of the fallopian tube in contact with the ovary [60]. The OSE is comprised of a single type of cuboidal cell, whereas the FTE is a mix of ciliated and secretory cells. Cells are shed from the FTE into the peritoneal cavity and these cells can embed onto the ovarian surface. Such a migration of transformed cells from the FTE to the ovary, a site more supportive of proliferation, has been proposed to be the first step in the formation of HGSOC [60].

In contrast to the intestine and skin, which have been extensively studied as models of epithelial stem cell biology, considerably less is known about the stem cells present in the OSE and FTE. This is due to the difficulty of isolating and culturing these cells to allow molecular characterization [61]. Studies in mice and humans have shown that both populations of stem cells are regulated by Wnt signaling $[15,62]$. Furthermore, Wnt signaling is upregulated in ovarian tumors [63], and is an important contributor to the acquired resistance of ovarian cancers to chemotherapeutics, a key factor in the high mortality of ovarian cancer [64-66]. Given the significance of RSPO/ LGR activity in increasing WNT signaling, it is likely that RSPO and LGR proteins also factors into tumor formation and chemoresistance in the OSE and FTE.

\section{LGR5 and RSPO1 function in OSE stem cells}

LGR5 is expressed in stem cells in the mouse OSE starting in embryogenesis and continuing into adulthood $[67,68]$. In the adult mouse, LGR5 is found in cell populations that co-express CD33, ALDH, and $\mathrm{Ki} 67$ $[12,67]$. The OSE ruptures to allow release of the oocyte during ovulation, and LGR5 was expressed in regions where rupture occurs, consistent with a role for stem cells in tissue repair [67]. LGR5-expressing OSE stem cells exhibited increased tumorigenicity in a TP53- and RB1deficient background, suggesting that these cells may mediate tumor formation [12].

The expression pattern of RSPO1 in the ovary and its stimulation of cell growth indicates a likely role in stem cell regulation. It is expressed broadly in the developing mouse ovary during embryogenesis, where it is essential for female gonad development [69]. After birth it becomes limited to a subset of cells that includes the OSE [70]. Given that LGR5 is also expressed in this cell population [67], it appears that the niche for OSE stem cells is either adjacent differentiated cells, similar to the Paneth cells intercalated among stem cells in the intestine, or the $\mathrm{LGR}^{+}$cells themselves through an autocrine signaling mechanism. Increasing levels of RSPO1 in the mouse ovary by expression from the $S f 1$ promoter produced granulosa cell tumors [70]. This is analogous to the findings that overexpression of RSPOs in the intestine causes hyperplasia [36-38], and support the finding that RSPO1 is an oncogene when expressed at elevated levels [18].

\section{RSPO1 and LGR6 function in fallopian tube stem cells}

The predominant cell types in the FTE are secretory and ciliated cells, comprising $90 \%$ of the population. There is a third type of cell, the peg cell, which is a candidate for the role of FTE stem cell. Peg cells are narrow, undifferentiated cells concentrated in the fimbria that are capable of self-renewal and clonal growth (Figure 2). Isolated human peg cells can grow into spheroids that produce secretory and ciliated cells, indicating that they are multipotent [71]. Peg cells can be distinguished from other cells in the FTE by their expression of CD44 and cytokeratin 5 (KRT5). Importantly, examination of clinical samples from patients with invasive serous carcinomas were positive for CD44 and KRT5, indicating that peg cells may be an important FTE cell population in the formation of ovarian tumors [71].

Analysis of cultured fallopian tube stem cells points to a role for RSPO1 signaling. Kessler et al. [15] isolated $\mathrm{Ki} 67^{+}$fallopian tube epithelial cells from patient samples and grew them into organoids in vitro using a cocktail of growth factors that included Wnt3A, EGF, and FGF. The organoids contained both ciliated and secretory cells, suggesting recapitulation of the FTE. Addition of RSPO1 to the growth medium increased Wnt signaling, the number of organoids, and organoid size [15]. In contrast to the OSE, which expresses $L G R 5$ [12], microarray and whole-genome sequence analysis of FTE organoids revealed elevated expression of LGR6 but not LGR5 [15, 72]. LGR6 was found to reside in a multipotent cell population in organoids that expressed the proliferation marker $\operatorname{Ki} 67$ [15, 72]. When stem cells in organoids were induced to differentiate by blocking Notch signaling with the $\gamma$-secretase inhibitor DBZ, LGR6 expression was reduced, suggesting that loss of stem cell self-renewal involves downregulation of $L G R 6$ expression [15].

\section{Expression of $L G R 5, L G R 6, R S P O 1$, and $R S P O 2$ in high grade serous ovarian cancer}

Despite the evidence that LGR5 is the major RSPO receptor in OSE stem cells and LGR6 is the primary receptor in FTE stem cells, data from The Cancer Genome Atlas (TCGA) suggest that both may be important in HGSOC. Both genes are amplified at a low frequency in ovarian cancers ( $L G R 54 \% ; L G R 68 \%$ ), but HGSOC is characterized by copy number variations at many loci, and neither gene stands out in this regard. No mutations were found in LGR5, and very few mutations were found in 
LGR6. More interesting is the observation that both genes are highly expressed in HGSOC compared to other tumors in the TCGA database (Figure 3). HGSOC, uterine, and colorectal cancers have the highest levels of $L G R 5$ mRNA, and HGSOC has the highest level of LGR6 expression.

As with LGR5 and LGR6, neither RSPO1 nor RSPO2 is mutated, although both exhibit low levels of amplification in HGSOC (RSPO1 9\%; RSPO2 24\%). The differences in expression at the $\mathrm{mRNA}$ level, however, are quite pronounced (Figure 4). HGSOC has the highest level of RSPO1 mRNA expression among all epithelial carcinomas, and one of the lowest levels of RSPO2 expression. Importantly, a genomewide association study identified polymorphisms in RSPOI as a risk factor for ovarian cancer, and specifically for tumors of serous histology [73]. There was no significant correlation between the mRNA expression of any of the four RSPOs and LGR5; only RSPO1 is significantly correlated with the expression of LGR6 in HGSOC (Pearson 0.478). Overall, the currently available data does not permit an assessment of the extent to which these ligands and receptors drive the high level of Wnt signaling that is found in $\operatorname{HGSOC}[63,66]$. Single cell studies are required to determine whether a given tumor cell expresses one or both LGR receptors, and whether tumor cells or a stromal cell type is the source of RPSO ligands. How expression of any of these molecules in tumor cells is linked to the magnitude of Wnt signaling remains to be addressed.

\section{Summary and conclusions}

Despite anatomical differences, epithelial stem cells in diverse tissues appear to be organized in similar ways. Differentiated niche cells are located in close proximity to the stem cells and secrete Wnt and RSPO ligands that regulate the canonical Wnt signaling pathway. The stem cells, in turn, express Wnt receptors FZD and LRP5/6, and RSPO receptors LGR4-6. The RSPO/LGR interaction serves to fine tune Wnt signaling. Although the RSPOs and LGR5-6 are dispensable in many cases for the steadystate functioning of tissues, they plays a role in recovery from injury, a process that requires elevated Wnt signaling. This suggests that RSPO/LGR activity, which is uniquely a vertebrate adaptation [74], may have evolved as a way to signal from the epithelium to resident stem cells to increase the rate of tissue growth. This advantageous aspect of RSPO/LGR activity has a parallel dark side: the risk of cancer if Wnt signaling is aberrantly elevated. Given their roles as Wnt signaling modulators and potential oncogenes, a key unresolved question is how RSPO and LGR expression activity is regulated. Recent work showing that Wnt signaling primes stem cells to receive RSPO ligands by increasing expression of its receptors provides an important insight into the cooperativity of Wnt and RSPO ligands in regulation of stem cells populations [38]. The study also found that RSPO ligands, not Wnts,

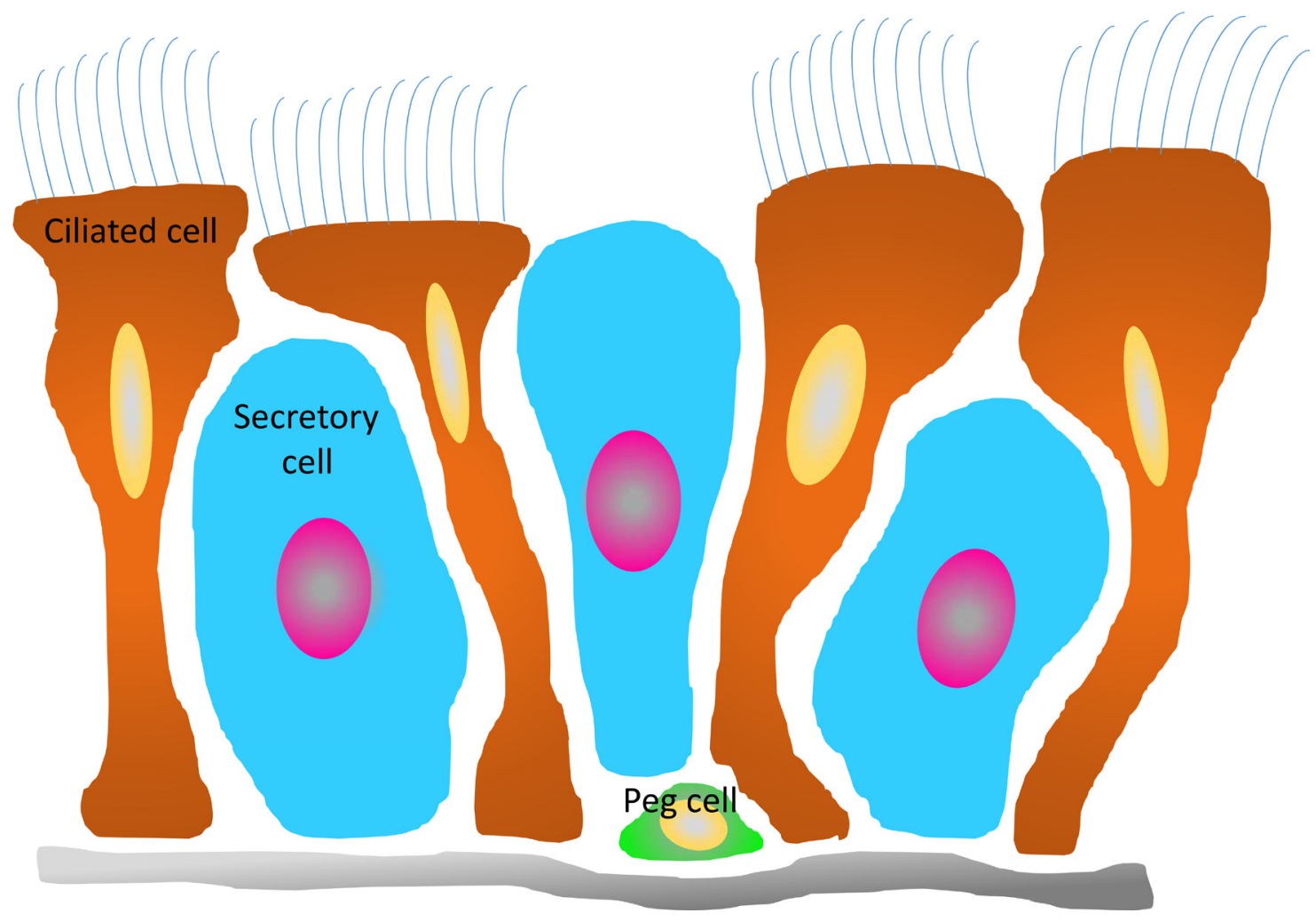

Figure 2: Schematic diagram of cellular organization of the fallopian tube epithelium. The PEG cells (green) have been identified as precursors of both the secretory (blue) and ciliated (brown) cells, but which cell type serves as the primary source of RSPO1/2 is unknown. 


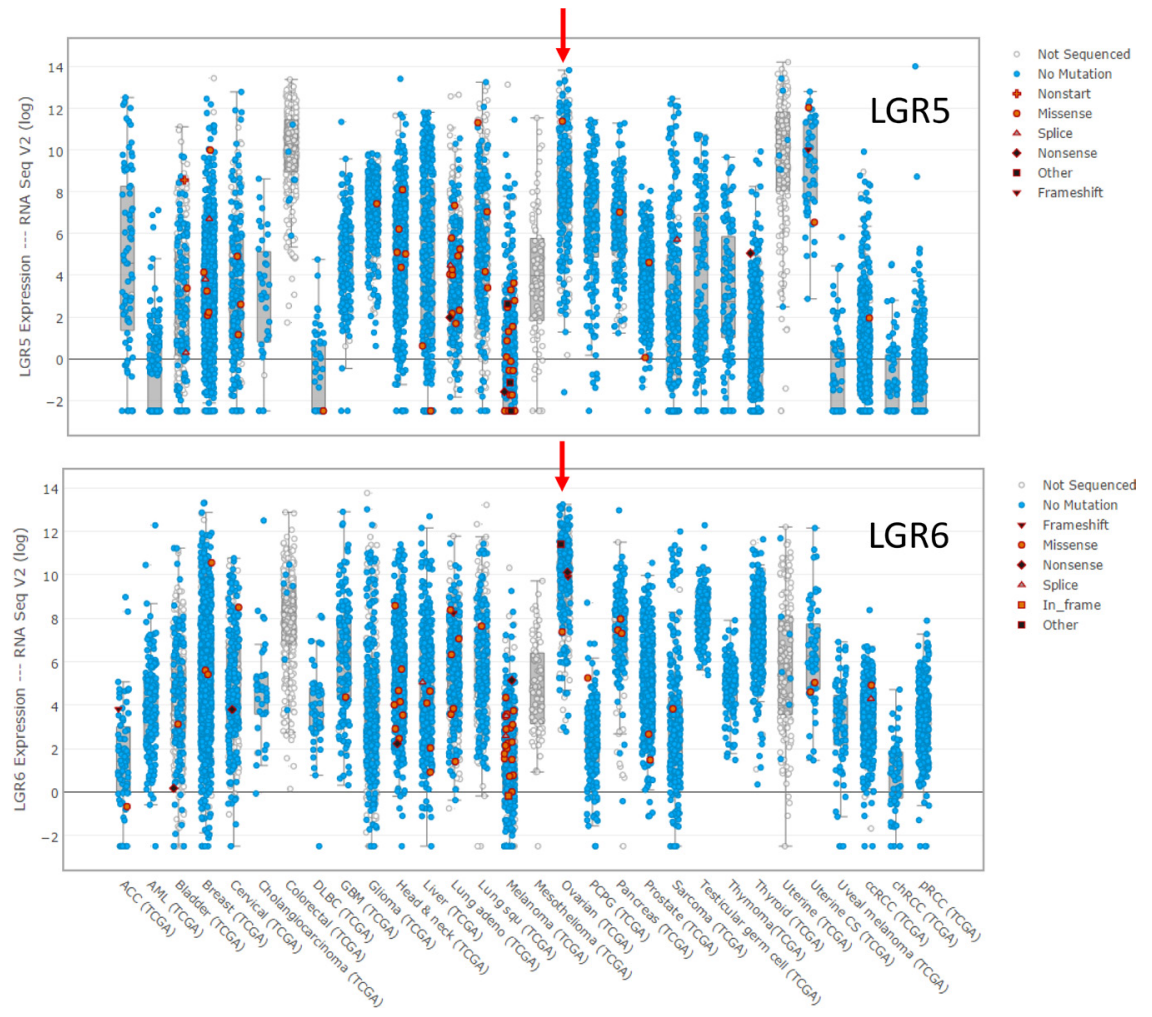

Figure 3: Expression of LGR5 and LGR6 at the mRNA level in the tumors in the TCGA database for which expression data is reported.
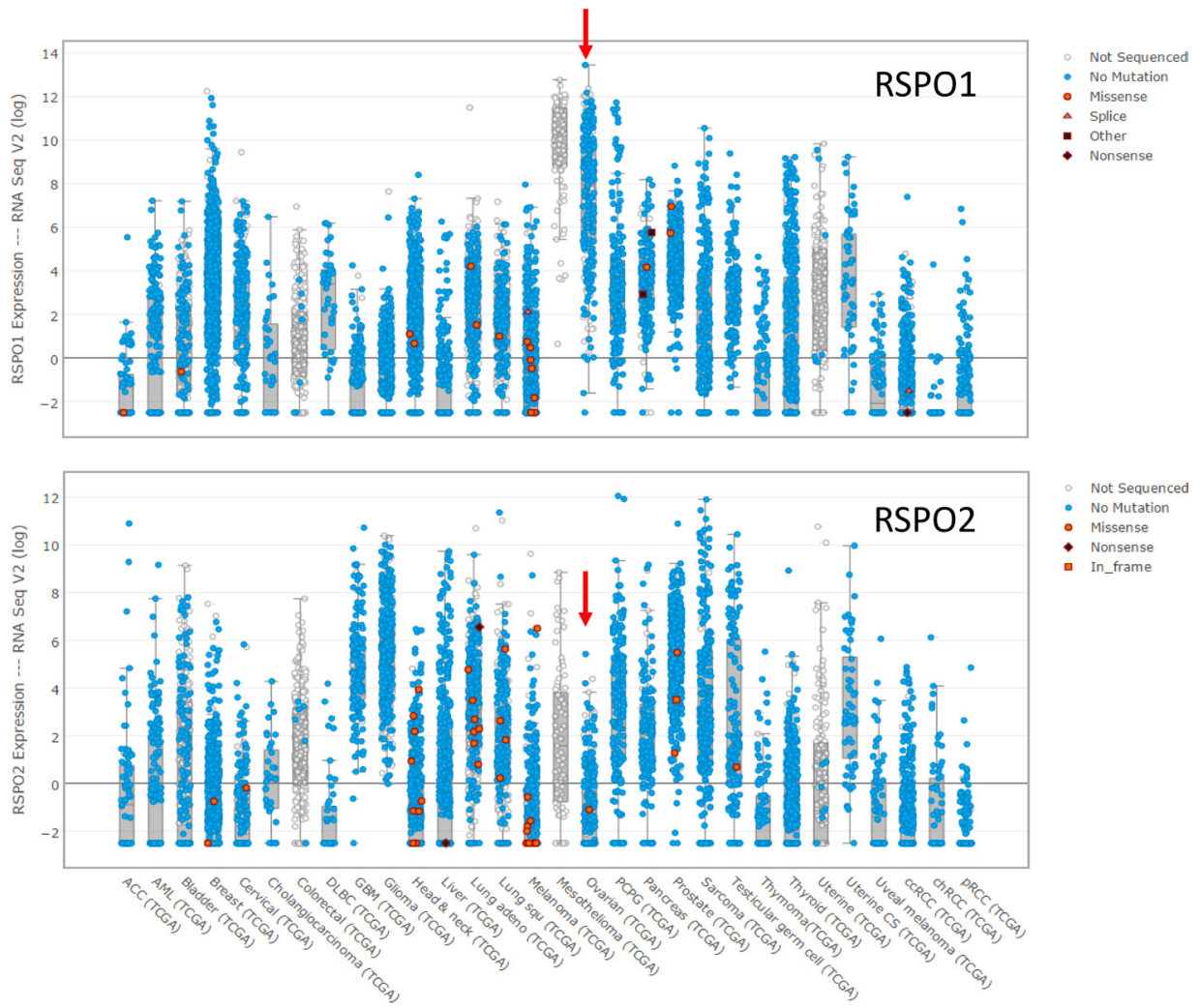

Figure 4: Expression of RSPO1 and RSPO2 at the mRNA level in the tumors in the TCGA database for which expression data is reported. 
were the key determinant of stem cell number [38]. The centrality of RSPO/LGR signaling in stem cells highlights the importance of further understanding the regulation of this pathway at the cellular level.

The identification of LGR5 and LGR6 as stem cell markers has presented a way to identify and isolate stem cells in a range of tissues. It also points toward a therapeutic strategy based on targeting these receptors to reduce cell proliferation. It may be possible to enhance selectivity by developing receptor antagonists that prevent the increase in stem cell number mediated by RSPOs without disabling the basal Wnt signaling required to keep normal stem cells alive. Such therapies would have potential benefits in the treatment of ovarian cancer, which is often diagnosed at a late stage and becomes resistant to chemotherapy [75]. To the extent that Wnt signaling reduces sensitivity to the platinum drugs and PARP inhibitors, inhibiting LGR/RSPO activity could make chemotherapeutics more effective in the management of HGSOC. The identification of the LGR/RSPO axis as a Wnt enhancer system in stem cells opens avenues to better isolate, characterize, and target a population of cells that is important to tumor formation and chemoresistance.

\section{CONFLICTS OF INTEREST}

The authors have no conflicts of interest to declare.

\section{FUNDING}

This work was supported in part by the Clayton Medical Research Foundation, Inc.

\section{REFERENCES}

1. Nusse R, Fuerer C, Ching W, Harnish K, Logan C, Zeng A, ten Berge D, Kalani Y. Wnt signaling and stem cell control. Cold Spring Harb Symp Quant Biol. 2008; 73:59-66.

2. Carmon KS, Gong X, Lin Q, Thomas A, Liu Q. R-spondins function as ligands of the orphan receptors LGR4 and LGR5 to regulate Wnt/beta-catenin signaling. Proc Natl Acad Sci USA. 2011; 108:11452-7.

3. de Lau W, Barker N, Low TY, Koo BK, Li VS, Teunissen H, Kujala P, Haegebarth A, Peters PJ, van de Wetering M, Stange DE, van Es JE, Guardavaccaro D, et al. Lgr5 homologues associate with Wnt receptors and mediate R-spondin signalling. Nature. 2011; 476:293-7.

4. Koo BK, Spit M, Jordens I, Low TY, Stange DE, van de Wetering M, van Es JH, Mohammed S, Heck AJ, Maurice MM, Clevers H. Tumour suppressor RNF43 is a stem-cell E3 ligase that induces endocytosis of Wnt receptors. Nature. 2012; 488:665-9.

5. Ruffner H, Sprunger J, Charlat O, Leighton-Davies J, Grosshans B, Salathe A, Zietzling S, Beck V, Therier M, Isken $\mathrm{A}$, Xie $\mathrm{Y}$, Zhang $\mathrm{Y}$, Hao $\mathrm{H}$, et al. R-Spondin potentiates Wnt/beta-catenin signaling through orphan receptors LGR4 and LGR5. PLoS One. 2012; 7:e40976.

6. Chen PH, Chen X, Lin Z, Fang D, He X. The structural basis of R-spondin recognition by LGR5 and RNF43. Genes Dev. 2013; 27:1345-50.

7. Xie Y, Zamponi R, Charlat O, Ramones M, Swalley S, Jiang X, Rivera D, Tschantz W, Lu B, Quinn L, Dimitri C, Parker J, Jeffery D, et al. Interaction with both ZNRF3 and LGR4 is required for the signalling activity of R-spondin. EMBO Rep. 2013; 14:1120-6.

8. Hao HX, Xie Y, Zhang Y, Charlat O, Oster E, Avello M, Lei H, Mickanin C, Liu D, Ruffner H, Mao X, Ma Q, Zamponi R, et al. ZNRF3 promotes Wnt receptor turnover in an R-spondin-sensitive manner. Nature. 2012; 485:195-200.

9. Barker N, van Es JH, Kuipers J, Kujala P, van den Born M, Cozijnsen M, Haegebarth A, Korving J, Begthel H, Peters PJ, Clevers H. Identification of stem cells in small intestine and colon by marker gene Lgr5. Nature. 2007; 449:1003-7.

10. Barker N, Rookmaaker MB, Kujala P, Ng A, Leushacke M, Snippert H, van de Wetering M, Tan S, Van Es JH, Huch M, Poulsom R, Verhaar MC, Peters PJ, et al. Lgr5(+ve) stem/ progenitor cells contribute to nephron formation during kidney development. Cell Rep. 2012; 2:540-52.

11. Jaks V, Barker N, Kasper M, van Es JH, Snippert HJ, Clevers H, Toftgard R. Lgr5 marks cycling, yet long-lived, hair follicle stem cells. Nat Genet. 2008; 40:1291-9.

12. Flesken-Nikitin A, Hwang CI, Cheng CY, Michurina TV, Enikolopov G, Nikitin AY. Ovarian surface epithelium at the junction area contains a cancer-prone stem cell niche. Nature. 2013; 495:241-5.

13. Plaks V, Brenot A, Lawson DA, Linnemann JR, Van Kappel EC, Wong KC, de Sauvage F, Klein OD, Werb Z. Lgr5-expressing cells are sufficient and necessary for postnatal mammary gland organogenesis. Cell Rep. 2013; 3:70-8.

14. Snippert HJ, Haegebarth A, Kasper M, Jaks V, van Es JH, Barker N, van de Wetering M, van den Born M, Begthel $H$, Vries RG, Stange DE, Toftgard R, Clevers H. Lgr6 marks stem cells in the hair follicle that generate all cell lineages of the skin. Science. 2010; 327:1385-9.

15. Kessler M, Hoffmann $\mathrm{K}$, Brinkmann $\mathrm{V}$, Thieck $\mathrm{O}$, Jackisch S, Toelle B, Berger H, Mollenkopf HJ, Mangler M, Sehouli J, Fotopoulou C, Meyer TF. The Notch and Wnt pathways regulate stemness and differentiation in human fallopian tube organoids. Nat Commun. 2015; 6:8989.

16. Lehoczky JA, Tabin CJ. Lgr6 marks nail stem cells and is required for digit tip regeneration. Proc Natl Acad Sci USA. 2015; 112:13249-54.

17. Blaas L, Pucci F, Messal HA, Andersson AB, Josue Ruiz E, Gerling M, Douagi I, Spencer-Dene B, Musch A, Mitter R, Bhaw L, Stone R, Bornhorst D, et al. Lgr6 labels a rare population of mammary gland progenitor cells that are able to originate luminal mammary tumours. Nat Cell Biol. 2016; 18:1346-56. 
18. Seshagiri S, Stawiski EW, Durinck S, Modrusan Z, Storm EE, Conboy CB, Chaudhuri S, Guan Y, Janakiraman V, Jaiswal BS, Guillory J, Ha C, Dijkgraaf GJ, et al. Recurrent R-spondin fusions in colon cancer. Nature. 2012; 488: 660-4.

19. Steffen JS, Simon E, Warneke V, Balschun K, Ebert M, Rocken C. LGR4 and LGR6 are differentially expressed and of putative tumor biological significance in gastric carcinoma. Virchows Arch. 2012; 461:355-65.

20. Michelotti G, Jiang X, Sosa JA, Diehl AM, Henderson BB. LGR5 is associated with tumor aggressiveness in papillary thyroid cancer. Oncotarget. 2015; 6:34549-60. https://doi. org/10.18632/oncotarget.5330.

21. Gong X, Yi J, Carmon KS, Crumbley CA, Xiong W, Thomas A, Fan X, Guo S, An Z, Chang JT, Liu QJ. Aberrant RSPO3-LGR4 signaling in Keap1-deficient lung adenocarcinomas promotes tumor aggressiveness. Oncogene. 2015; 34:4692-701.

22. Van Schoore G, Mendive F, Pochet R, Vassart G. Expression pattern of the orphan receptor LGR4/GPR48 gene in the mouse. Histochem Cell Biol. 2005; 124:35-50.

23. Li Z, Zhang W, Mulholland MW. LGR4 and Its Role in Intestinal Protection and Energy Metabolism. Front Endocrinol (Lausanne). 2015; 6:131.

24. Mustata RC, Van Loy T, Lefort A, Libert F, Strollo S, Vassart G, Garcia MI. Lgr4 is required for Paneth cell differentiation and maintenance of intestinal stem cells ex vivo. EMBO Rep. 2011; 12:558-64.

25. Mohri Y, Kato S, Umezawa A, Okuyama R, Nishimori K. Impaired hair placode formation with reduced expression of hair follicle-related genes in mice lacking Lgr4. Dev Dyn. 2008; 237:2235-42.

26. Luo W, Rodriguez M, Valdez JM, Zhu X, Tan K, Li D, Siwko S, Xin L, Liu M. Lgr4 is a key regulator of prostate development and prostate stem cell differentiation. Stem Cells. 2013; 31:2492-505.

27. Wang Y, Dong J, Li D, Lai L, Siwko S, Li Y, Liu M. Lgr4 regulates mammary gland development and stem cell activity through the pluripotency transcription factor Sox 2 . Stem Cells. 2013; 31:1921-31.

28. Wu J, Xie N, Xie K, Zeng J, Cheng L, Lei Y, Liu Y, Song L, Dong D, Chen Y, Zeng R, Nice EC, Huang C, et al. GPR48, a poor prognostic factor, promotes tumor metastasis and activates beta-catenin/TCF signaling in colorectal cancer. Carcinogenesis. 2013; 34:2861-9.

29. Xu P, Dang Y, Wang L, Liu X, Ren X, Gu J, Liu M, Dai X, Ye X. Lgr4 is crucial for skin carcinogenesis by regulating MEK/ERK and Wnt/beta-catenin signaling pathways. Cancer Lett. 2016; 383:161-70.

30. Liang F, Yue J, Wang J, Zhang L, Fan R, Zhang H, Zhang Q. GPCR48/LGR4 promotes tumorigenesis of prostate cancer via PI3K/Akt signaling pathway. Med Oncol. 2015; 32:49.

31. Gao Y, Kitagawa K, Hiramatsu Y, Kikuchi H, Isobe T, Shimada M, Uchida C, Hattori T, Oda T, Nakayama K,
Nakayama KI, Tanaka T, Konno H, et al. Up-regulation of GPR48 induced by down-regulation of p27Kip1 enhances carcinoma cell invasiveness and metastasis. Cancer Res. 2006; 66:11623-31.

32. Sato T, van Es JH, Snippert HJ, Stange DE, Vries RG, van den Born M, Barker N, Shroyer NF, van de Wetering M, Clevers H. Paneth cells constitute the niche for Lgr5 stem cells in intestinal crypts. Nature. 2011; 469:415-8.

33. Barker N, van Oudenaarden A, Clevers H. Identifying the stem cell of the intestinal crypt: strategies and pitfalls. Cell Stem Cell. 2012; 11:452-60.

34. Baker AM, Graham TA, Elia G, Wright NA, RodriguezJusto M. Characterization of LGR5 stem cells in colorectal adenomas and carcinomas. Sci Rep. 2015; 5:8654.

35. Sato T, Vries RG, Snippert HJ, van de Wetering $M$, Barker N, Stange DE, van Es JH, Abo A, Kujala P, Peters PJ, Clevers H. Single Lgr5 stem cells build cryptvillus structures in vitro without a mesenchymal niche. Nature. 2009; 459:262-5.

36. Kim KA, Kakitani M, Zhao J, Oshima $\mathrm{T}$, Tang $\mathrm{T}$, Binnerts M, Liu Y, Boyle B, Park E, Emtage P, Funk WD, Tomizuka K. Mitogenic influence of human R-spondin1 on the intestinal epithelium. Science. 2005; 309:1256-9.

37. Hilkens J, Timmer NC, Boer M, Ikink GJ, Schewe M, Sacchetti A, Koppens MA, Song JY, Bakker ER. RSPO3 expands intestinal stem cell and niche compartments and drives tumorigenesis. Gut. 2016.

38. Yan KS, Janda CY, Chang J, Zheng GXY, Larkin KA, Luca VC, Chia LA, Mah AT, Han A, Terry JM, Ootani A, Roelf $\mathrm{K}$, Lee $\mathrm{M}$, et al. Non-equivalence of Wnt and R-spondin ligands during Lgr5+ intestinal stem-cell selfrenewal. Nature. 2017.

39. Lavery R, Chassot AA, Pauper E, Gregoire EP, Klopfenstein M, de Rooij DG, Mark M, Schedl A, Ghyselinck NB, Chaboissier MC. Testicular differentiation occurs in absence of R-spondin1 and Sox9 in mouse sex reversals. PLoS Genet. 2012; 8:e1003170.

40. Tomizuka K, Horikoshi K, Kitada R, Sugawara Y, Iba Y, Kojima A, Yoshitome A, Yamawaki K, Amagai M, Inoue A, Oshima T, Kakitani M. R-spondin1 plays an essential role in ovarian development through positively regulating Wnt-4 signaling. Hum Mol Genet. 2008; 17:1278-91.

41. Chassot AA, Bradford ST, Auguste A, Gregoire EP, Pailhoux E, de Rooij DG, Schedl A, Chaboissier MC. WNT4 and RSPO1 together are required for cell proliferation in the early mouse gonad. Development. 2012; 139:4461-72.

42. Parma P, Radi O, Vidal V, Chaboissier MC, Dellambra E, Valentini S, Guerra L, Schedl A, Camerino G. R-spondin1 is essential in sex determination, skin differentiation and malignancy. Nat Genet. 2006; 38:1304-9.

43. Tomaselli S, Megiorni F, Lin L, Mazzilli MC, Gerrelli D, Majore S, Grammatico P, Achermann JC. Human RSPO1/Rspondin 1 is expressed during early ovary development and augments beta-catenin signaling. PLoS One. 2011; 6:e16366. 
44. Cordero JB, Sansom OJ. Wnt signalling and its role in stem cell-driven intestinal regeneration and hyperplasia. Acta Physiol (Oxf). 2012; 204:137-43.

45. Bhanja P, Saha S, Kabarriti R, Liu L, Roy-Chowdhury N, Roy-Chowdhury J, Sellers RS, Alfieri AA, Guha C. Protective role of R-spondin1, an intestinal stem cell growth factor, against radiation-induced gastrointestinal syndrome in mice. PLoS One. 2009; 4:e8014.

46. Metcalfe C, Kljavin NM, Ybarra R, de Sauvage FJ. Lgr5+ stem cells are indispensable for radiation-induced intestinal regeneration. Cell Stem Cell. 2014; 14:149-59.

47. Jung JG, Shih IM, Park JT, Gerry E, Kim TH, Ayhan A, Handschuh K, Davidson B, Fader AN, Selleri L, Wang TL. Ovarian Cancer Chemoresistance Relies on the Stem Cell Reprogramming Factor PBX1. Cancer Res. 2016; 76:6351-61.

48. Izumiya $\mathrm{M}$, Kabashima $\mathrm{A}$, Higuchi $\mathrm{H}$, Igarashi $\mathrm{T}$, Sakai G, Iizuka H, Nakamura S, Adachi M, Hamamoto Y, Funakoshi S, Takaishi H, Hibi T. Chemoresistance is associated with cancer stem cell-like properties and epithelial-to-mesenchymal transition in pancreatic cancer cells. Anticancer Res. 2012; 32:3847-53.

49. Liu YS, Hsu HC, Tseng KC, Chen HC, Chen SJ. Lgr5 promotes cancer stemness and confers chemoresistance through ABCB1 in colorectal cancer. Biomed Pharmacother. 2013; 67:791-9.

50. Xi HQ, Cui JX, Shen WS, Wu XS, Bian SB, Li JY, Song Z, Wei B, Chen L. Increased expression of Lgr5 is associated with chemotherapy resistance in human gastric cancer. Oncol Rep. 2014; 32:181-8.

51. Forgham H, Johnson D, Carter N, Veuger S, CarrWilkinson J. Stem Cell Markers in Neuroblastoma-An Emerging Role for LGR5. Front Cell Dev Biol. 2015; 3:77.

52. Barker N, Tan S, Clevers H. Lgr proteins in epithelial stem cell biology. Development. 2013; 140:2484-94.

53. Hsu YC, Li L, Fuchs E. Emerging interactions between skin stem cells and their niches. Nat Med. 2014; 20:847-56.

54. Fuchs E, Horsley V. More than one way to skin. Genes Dev. 2008; 22:976-85.

55. Lim X, Tan SH, Koh WL, Chau RM, Yan KS, Kuo CJ, van Amerongen R, Klein AM, Nusse R. Interfollicular epidermal stem cells self-renew via autocrine Wnt signaling. Science. 2013; 342:1226-30.

56. Li N, Liu S, Zhang HS, Deng ZL, Zhao HS, Zhao Q, Lei XH, Ning LN, Cao YJ, Wang HB, Duan EK. Exogenous R-Spondin1 Induces Precocious Telogen-to-Anagen Transition in Mouse Hair Follicles. Int J Mol Sci. 2016; 17.

57. Chua AW, Ma D, Gan SU, Fu Z, Han HC, Song C, Sabapathy K, Phan TT. The role of R-spondin2 in keratinocyte proliferation and epidermal thickening in keloid scarring. J Invest Dermatol. 2011; 131:644-54.

58. Cadieu E, Neff MW, Quignon P, Walsh K, Chase K, Parker HG, Vonholdt BM, Rhue A, Boyko A, Byers A, Wong A, Mosher DS, Elkahloun AG, et al. Coat variation in the domestic dog is governed by variants in three genes. Science. 2009; 326:150-3.

59. Parker HG, Chase K, Cadieu E, Lark KG, Ostrander EA. An insertion in the RSPO2 gene correlates with improper coat in the Portuguese water dog. J Hered. 2010; 101:612-7.

60. Crum CP, Drapkin R, Kindelberger D, Medeiros F, Miron A, Lee Y. Lessons from BRCA: the tubal fimbria emerges as an origin for pelvic serous cancer. Clin Med Res. 2007; $5: 35-44$.

61. Ng A, Barker N. Ovary and fimbrial stem cells: biology, niche and cancer origins. Nat Rev Mol Cell Biol. 2015.

62. Usongo M, Farookhi R. beta-catenin/Tcf-signaling appears to establish the murine ovarian surface epithelium (OSE) and remains active in selected postnatal OSE cells. BMC Dev Biol. 2012; 12:17.

63. Arend RC, Londono-Joshi AI, Straughn JM Jr, Buchsbaum DJ. The Wnt/beta-catenin pathway in ovarian cancer: a review. Gynecol Oncol. 2013; 131:772-9.

64. Barghout SH, Zepeda N, Xu Z, Steed H, Lee CH, Fu Y. Elevated beta-catenin activity contributes to carboplatin resistance in A2780cp ovarian cancer cells. Biochem Biophys Res Commun. 2015; 468:173-8.

65. Chau WK, Ip CK, Mak AS, Lai HC, Wong AS. c-Kit mediates chemoresistance and tumor-initiating capacity of ovarian cancer cells through activation of Wnt/beta-catenin-ATPbinding cassette G2 signaling. Oncogene. 2013; 32:2767-81.

66. Nagaraj AB, Joseph P, Kovalenko O, Singh S, Armstrong A, Redline R, Resnick K, Zanotti K, Waggoner S, DiFeo A. Critical role of $\mathrm{Wnt} /$ beta-catenin signaling in driving epithelial ovarian cancer platinum resistance. Oncotarget. 2015; 6:23720-34. https://doi.org/10.18632/oncotarget.4690.

67. Ng A, Tan S, Singh G, Rizk P, Swathi Y, Tan TZ, Huang RY, Leushacke M, Barker N. Lgr5 marks stem/progenitor cells in ovary and tubal epithelia. Nat Cell Biol. 2014; 16:745-57.

68. Rastetter RH, Bernard P, Palmer JS, Chassot AA, Chen H, Western PS, Ramsay RG, Chaboissier MC, Wilhelm D. Marker genes identify three somatic cell types in the fetal mouse ovary. Dev Biol. 2014; 394:242-52.

69. Chassot AA, Ranc F, Gregoire EP, Roepers-Gajadien HL, Taketo MM, Camerino G, de Rooij DG, Schedl A, Chaboissier MC. Activation of beta-catenin signaling by Rspo1 controls differentiation of the mammalian ovary. Hum Mol Genet. 2008; 17:1264-77.

70. De Cian MC, Pauper E, Bandiera R, Vidal VP, Sacco S, Gregoire EP, Chassot AA, Panzolini C, Wilhelm D, Pailhoux E, Youssef SA, de Bruin A, Teerds K, et al. Amplification of R-spondin1 signaling induces granulosa cell fate defects and cancers in mouse adult ovary. Oncogene. 2017; 36:208-18.

71. Paik DY, Janzen DM, Schafenacker AM, Velasco VS, Shung MS, Cheng D, Huang J, Witte ON, Memarzadeh S. Stem-like epithelial cells are concentrated in the distal end of the fallopian tube: a site for injury and serous cancer initiation. Stem Cells. 2012; 30:2487-97. 
72. Yamamoto Y, Ning G, Howitt BE, Mehra K, Wu L, Wang X, Hong Y, Kern F, Wei TS, Zhang T, Nagarajan N, Basuli D, Torti S, et al. In vitro and in vivo correlates of physiological and neoplastic human Fallopian tube stem cells. J Pathol. 2016; 238:519-30.

73. Kuchenbaecker KB, Ramus SJ, Tyrer J, Lee A, Shen HC, Beesley J, Lawrenson K, McGuffog L, Healey S, Lee JM, Spindler TJ, Lin YG, Pejovic T, et al. Identification of six new susceptibility loci for invasive epithelial ovarian cancer. Nat Genet. 2015.
74. de Lau WB, Snel B, Clevers HC. The R-spondin protein family. Genome Biol. 2012; 13:242.

75. Matulonis UA, Sood AK, Fallowfield L, Howitt BE, Sehouli J, Karlan BY. Ovarian cancer. Nat Rev Dis Primers. $2016 ; 2: 16061$. 